American Journal of Applied Sciences 6 (6): 1139-1142, 2009

ISSN 1546-9239

(C) 2009 Science Publications

\title{
Correlation Between Steady State and Impulse Earth Resistance Values
}

\author{
N. Mohamad Nor and R. Rajab \\ Faculty of Engineering, Multimedia University, Malaysia
}

\begin{abstract}
This study presented experimental results of earthing systems under low-magnitude currents and under high impulse currents. The details of the measuring circuit involved for both types of testing were described. Three field sites were selected. At each site, three earth electrodes configurations were used. This makes up to nine earthing systems. From both low magnitude and impulse tests, the correlation between the steady state earth resistance value and the earth resistance under fast impulse currents can be observed. The relation between the calculated and measured steady state earth resistance is also shown in this study.
\end{abstract}

Key words: Earthing systems, low magnitude current, low frequency currents, fast impulses

\section{INTRODUCTION}

It is known from previous studies that, under high impulse currents, soil non-linearity or reduced earth resistance values versus steady state values are observed $^{[1-5]}$. It has also been found in the literature ${ }^{[1-5]}$ that the magnitude of the electric field $\mathrm{E}_{\mathrm{c}}$, determines the degree of non-linearity and soil resistance reduction. $\mathrm{E}_{\mathrm{c}}$ magnitudes in the range of $1.3-20 \mathrm{kV} \mathrm{cm}^{-1[1-4]}$ show that the degree of non-linearity or reduced earth resistance values under impulse conditions is not very clear and needs further investigation. Moreover, it has been observed in $^{[1-5]}$ that a smaller resistance reduction occurs for earth electrodes of low steady-state earth resistance, whereas, higher resistance reduction occurs in high steady state earth resistance. This study determines the correlation by conducting tests on practical earthing systems using both low-magnitude current test to obtain for the steady state earth resistance value and high-magnitude impulse applications for the impulse resistance.

From the tests, it was found that the degree of ionisation in soils is dependent upon the steady state, $R_{D C}$ value; the lower $R_{D C}$, the lower the ionisation effect on the earthing system under high impulse currents, thus the impulse resistance becomes less dependent on current magnitudes.

Steady state earth resistance values: For this section, the earth resistance values were obtained by calculation and measurements at low magnitude currents.

Calculated values: Three field sites were selected, where for each site, the soil resistivity was measured using the Wenner Method as outlined in the standards, namely ${ }^{[6-8]}$.

The soil resistivity values obtained from the measurements were then interpreted as two-layer soil using the master curves ${ }^{[9]}$ and a Genetic Algorithm $(\mathrm{GA})^{[10]}$, where the results are shown in Table 1 .

Based on the resistivity values obtained from the master curves and the GA, the earth resistance values are calculated using the formulas ${ }^{[11]}$ for the earthing systems which consist of simple rod configurations of 2, 3 and 4 rods. All of these copper rods are connected with wires to ensure connectivity. Table 2 shows the arrangement for the earth electrodes consisting of 2, 3 and 4 rods and the calculated and measured earth resistance values. Small differences are observed between the measured earth resistance values and values obtained the master curves and the GA.

As can be shown from Table 2, the earth resistance values obtained for site 1 are the lowest since it has the lowest soil resistivity values. Also, as expected the resistance values for the 4 rods configuration are the lowest, since it has the largest surface area.

Table 1: Soil resistivity values interpreted using the master curves and GA into two layers of soil

\begin{tabular}{lrr}
\hline & Master curves & $(\mathrm{GA})^{[5]}$ \\
\hline Site 1 & & \\
Upper resistivity, $\rho_{1}(\Omega \mathrm{m})$ & 540.00 & 525.60 \\
Lower resistivity, $\rho_{2}(\Omega \mathrm{m})$ & 108.25 & 112.50 \\
Thickness, $\mathrm{h}(\mathrm{m})$ & 0.80 & 0.83 \\
Site 2 & & \\
Upper resistivity, $\rho_{1}(\Omega \mathrm{m})$ & 780.00 & 806.40 \\
Lower resistivity, $\rho_{2}(\Omega \mathrm{m})$ & 195.00 & 180.80 \\
Thickness, h $(\mathrm{m})$ & 1.30 & 1.34 \\
Site 3 & & \\
Upper resistivity, $\rho_{1}(\Omega \mathrm{m})$ & 720.00 & 709.40 \\
Lower resistivity, $\rho_{2}(\Omega \mathrm{m})$ & 288.40 & 290.60 \\
Thickness, $h(\mathrm{~m})$ & 1.25 & 1.30 \\
\hline
\end{tabular}

Corresponding Author: N. Mohamad Nor, Faculty of Engineering, Multimedia University, Malaysia 
Table 2: Calculated earth resistance values

\begin{tabular}{|c|c|c|c|}
\hline \multirow[b]{2}{*}{ Configurations } & \multicolumn{2}{|c|}{ Calculated } & \multirow[b]{2}{*}{ Measured } \\
\hline & $\begin{array}{l}\mathrm{R}_{\text {calc }}(\Omega) \text { where } \\
\text { the resistivity } \\
\text { from GA }\end{array}$ & $\begin{array}{l}\mathrm{R}_{\text {calc }}(\Omega) \text { where the } \\
\text { resistivity values } \\
\text { are obtained from } \\
\text { master curves }\end{array}$ & \\
\hline Site 1 & & & \\
\hline $\begin{array}{ll}0 & 0 \\
0 & 0\end{array}$ & 53.60 & 51.08 & 49.10 \\
\hline $0^{0} 0$ & 40.10 & 38.22 & 36.60 \\
\hline$\bigcirc 0$ & 32.30 & 30.74 & 29.40 \\
\hline Site 2 & & & \\
\hline $\begin{array}{ll}0 & 0 \\
0 & 0\end{array}$ & 126.34 & 126.20 & 122.23 \\
\hline $0^{0} 0$ & 94.58 & 94.57 & 95.27 \\
\hline$\bigcirc 0$ & 76.20 & 76.23 & 72.67 \\
\hline Site 3 & & & \\
\hline $\begin{array}{ll}0 & 0 \\
0 & 0\end{array}$ & 153.40 & 149.03 & 151.00 \\
\hline $0^{0} 0$ & 115.67 & 112.39 & 121.30 \\
\hline$\bigcirc 0$ & 93.55 & 90.89 & 95.73 \\
\hline
\end{tabular}

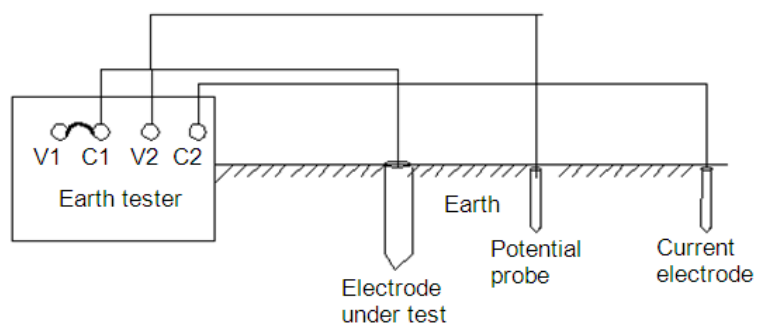

Fig. 1: Earth resistance measurement test circuit

Even though the earth resistance values have been calculated, it is still important to obtain the earth resistance by measurements at field sites to determine the actual resistance of the ground connections. These calculated values are also compared with the measurements of steady state earth resistance, which are shown in the Table 2.

Measured values: In this study, the most common earth resistance measurement, which is a Fall-ofPotential (FOP) method ${ }^{[6]}$, is adopted. The method involves passing a current into the electrode to be measured and noting the influence of this current in terms of the voltage between the ground under test and a test potential electrode (Fig. 1). The FOP method consists of plotting the ratio of $\mathrm{V} / \mathrm{I}=\mathrm{R}$ as a function of probe spacing $\mathrm{x}$. The potential electrode is moved away from the electrode under test in steps. A value of impedance is obtained at each step.

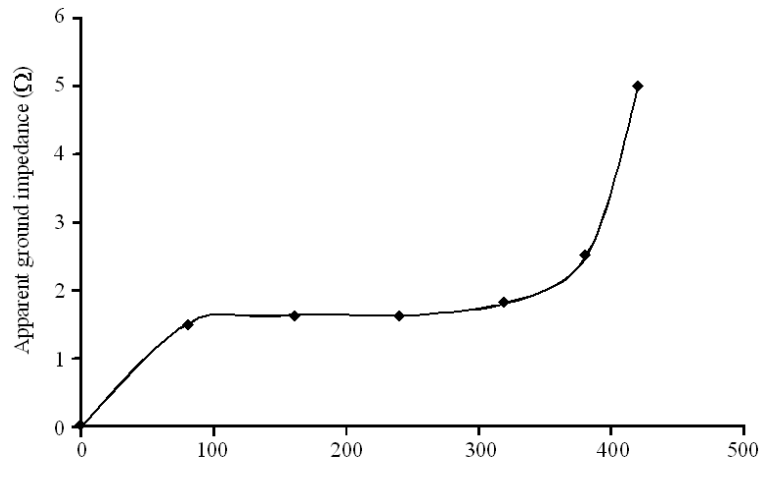

Distance between potential probe and eath electrode (m)

Fig. 2: Typical plot of ground impedance versus distance between the potential probe and the electrode under test

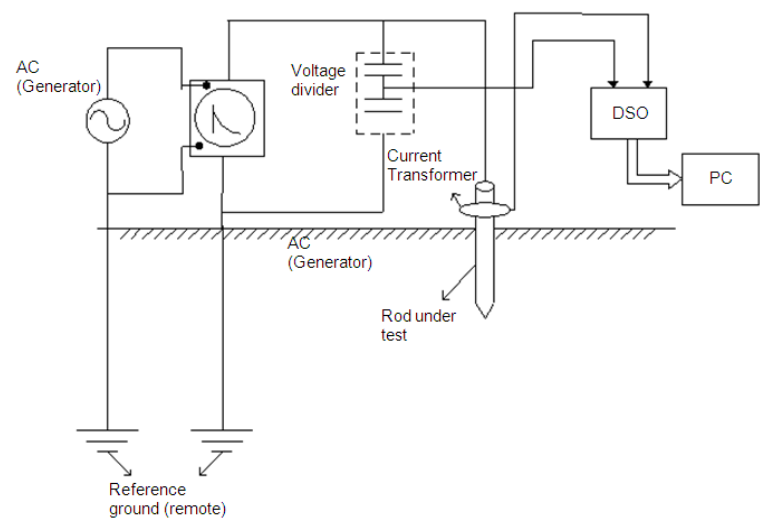

Fig. 3: Test circuit for impulse tests on earth electrode

This impedance is plotted as a function of distance and the value in ohms at which this plotted curve appears to level out is taken as the impedance value of the ground under test (Fig. 2).

The measured earth resistance results are shown in Table 2. As can be shown in Table 2, the percentage difference between the calculated and measured earth resistance for each earthing system is found to be below $10 \%$. The close results between the calculated and measured values show that the formulas developed by ${ }^{[11]}$ can be used to calculate the earth resistance values for preliminary designs. Also, the interpretation of soil resistivity values as 2 layers may be adequate to obtain the resistance values of earthing systems.

Earth resistance values under high impulse currents: Figure 3 shows a proposed test circuit that is suitable for impulse testing. The work undertaken in this study relies heavily on the effectiveness of the experimental set up. The test circuit (Fig. 3) in this study consists of: 
- A combinational waveform impulse generator, giving the output voltage of $4 \mathrm{kV}, 1.2 / 50 \mu \mathrm{s}$ and the currents up to $3 \mathrm{kA}, 8 / 20 \mu \mathrm{s}$

- Voltage and current measurements, in which a voltage probe with a ratio of 1000: 1 and $40 \mathrm{~ns}$ response times is used and a current transformer with a sensitivity of 0.1 V/A with a response time of $20 \mathrm{~ns}$ is used for current measurement

- A data acquisition system and analysis routine consisting of the transducers (voltage probe and current transformer), measurement cables and recording instruments (i.e., Digital Storage Oscilloscope)

The measurement results: The measured steady state earth resistance values were shown in Table 2. Here, the measurement results of the earthing systems under high impulse currents are presented. The impulse voltages ranging from $0.5-4 \mathrm{kV}$ are injected on the earthing systems.

Voltage and current traces: Figure 4 shows the typical voltage and current traces of the earthing systems for two rods at site 1 at a charging voltage of $1.5 \mathrm{kV}$. Similar voltage and current traces were observed for other configurations and voltage levels. However, it was observed that the time to current peak, $\mathrm{t}_{\text {delay }}$ (Fig. 4) increases with the number of rods (Fig. 5). This is expected, since a higher number of rods has larger inductive effects, which becomes more significant for transient voltages.

Earth resistance values: The earth resistance values are determined by $\frac{V @ I_{\text {peak }}}{I_{\text {peak }}}$. Table 3 shows the earth resistance values obtained using both low magnitude currents and high impulse currents. As can be seen in Table 3, the $\mathrm{R}_{\text {impulse }}$ for the earthing systems in site 1 are found to be higher than the $R_{D C}$ values,

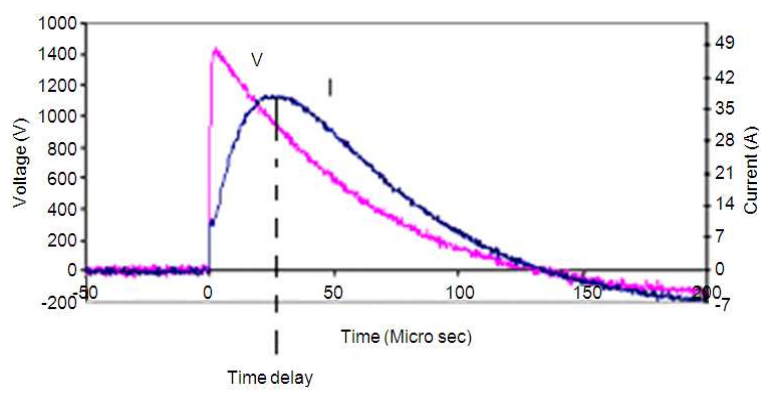

Fig. 4: Typical voltage and current traces for the earthing system at site 1 consisting of 2 rods and at a charging voltage of $1.5 \mathrm{kV}$ whereas there is a reduction in the earth resistance values for the earthing systems in sites 2 and 3 . The

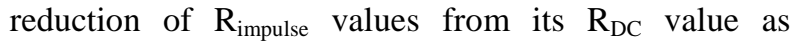
observed in sites 2 and 3 could be due to the ionization in soils, similar to some findings observed in previous study ${ }^{[1-5]}$. However, the $\mathrm{R}_{\text {impulse }}$ values for the earthing systems in site 1 , which has the lowest $R_{D C}$ are not affected by the ionisation, thus the $R_{\text {impulse }}$ values are found to be higher than $\mathrm{R}_{\mathrm{DC}}$. From these results it can be concluded that the degree of ionisation in soils is dependent upon the $\mathrm{R}_{\mathrm{DC}}$ value; the lower $\mathrm{R}_{\mathrm{DC}}$, the lower the ionisation effect on the earthing system under high impulse currents. Thus, the impulse resistance becomes less dependent on current magnitudes. This explains why the $R_{\text {impulse }}$ in earthing systems in site 1 are not affected by the ionisation process, thus, the $R_{\text {impulse }}$ is increased at high currents, rather than decreased. The highest increase is observed in the earthing system which consists of 4 rods, since it has the lowest $R_{D C}$ and thus is not affected by the ionisation process.

As has been defined $\mathrm{in}^{[1-5]}$, the magnitude of electric field at which the ionisation process is initiated is known as the critical electric field, $\mathrm{E}_{\mathrm{c}}$. This parameter contributes to the knowledge of the degree of resistance reduction in soil. The results obtained in this study can be explained by the simple relationship between the electric field, E and the current density, J,

Table 3: Percentage of reduction between $R_{D C}$ and $R_{\text {impulse }}$

\begin{tabular}{lrcc}
\hline & $\mathrm{R}_{\mathrm{DC}}(\Omega)$ & $\mathrm{R}_{\text {Impulse-average }}(\Omega)$ & $(\%)$ difference \\
\hline Site $\mathbf{1}$ & & & \\
2 rods & 49.10 & 49.11 & 0.02 \\
3 rods & 36.60 & 39.17 & 6.56 \\
4 rods & 29.40 & 31.17 & 5.67 \\
Site $\mathbf{2}$ & & & \\
2 rods & 122.23 & 95.40 & 12.24 \\
3 rods & 95.27 & 78.19 & 17.93 \\
4 rods & 72.67 & 59.07 & 18.72 \\
Site 3 & & & \\
2 rods & 151.00 & 134.37 & 11.01 \\
3 rods & 121.30 & 106.54 & 12.15 \\
4 rods & 90.89 & 81.24 & 15.14 \\
\hline
\end{tabular}

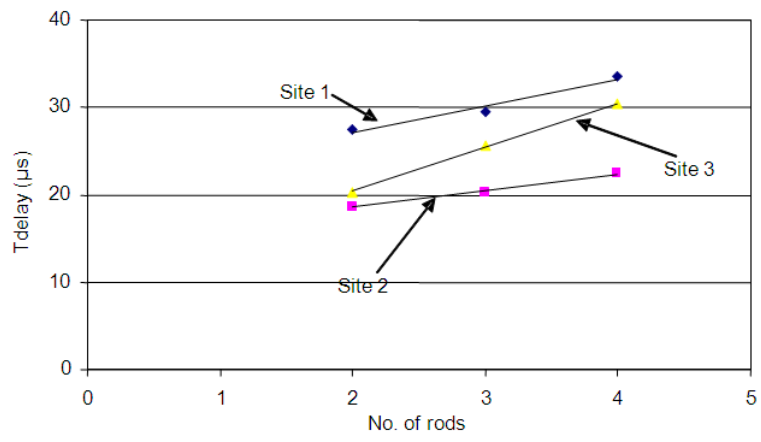

Fig. 5: $T_{\text {delay }}$ versus the number of rods and site (soil resistivity) 
$\mathrm{E}=\rho \mathrm{J}$, where $\rho$ is the soil resistivity. This equation shows that in order to have a high critical ionisation field, $E_{c}$, to cause a reduction in the earth resistance value, it will require higher current densities and a high resistivity value. As can be shown in Table 1, site 1 has the lowest resistivity, thus, it is expected to have the lowest $\mathrm{E}_{\mathrm{c}}$ and to experience the least ionisation in the soil.

\section{CONCLUSION}

In this study, measured earth resistance values were obtained for 9 earthing systems under steady state and transient conditions. The calculated earth resistance values were also presented and were found to be close to those measured under steady state conditions. It was also found that there is a correlation between $\mathrm{R}_{\mathrm{DC}}$ and $\mathrm{R}_{\text {impulse, }}$, where the resistance reduction under impulse conditions is highest for high $\mathrm{R}_{\mathrm{DC}}$.

\section{REFERENCES}

1. Mohamad Nor, N., A. Haddad and H. Griffiths, 2006. Characterisation of ionisation phenomena in soils under fast impulses. IEEE Trans. Power Delivery, 21: 353-361.

2. Bellaschi, P.L., R.E. Armington and A.E. Snowden, 1942. Impulse and 60-cycle characteristics of driven grounds-II'. AIEE Trans. Power Apparatus Syst., 61: 349-363.
3. Liew, A.C. and M. Darveniza, 1974. Dynamic model of impulse characteristics of concentrated earths. Proc. IEEE., 121: 123-135.

4. Vainer, A.L., 1965. Impulse characteristics of complex earth grids. Elektrichestvo, 3: 107-117.

5. Sonoda, T., H. Takesue, S. Sekioka, 2000. Measurement on surge characteristics of grounding resistance of counterpoises for impulse currents. 25th International Conference on Lightning Protection, Rhodes (Greece), Sep. 18-22, pp: 411-415.

6. ANSI/IEEE Std 80-2000, IEEE Guide for safety in AC substation grounding.

7. ANSI/IEEE Std 81-1983, IEEE Guide for measuring earth resistivity, ground impedance and earth surface potentials of a ground system.

8. ANSI/IEEE Std 142-1991, IEEE Recommended practice for grounding industrial and commercial power systems.

9. Orellana, E. and H.M. Mooney, 1966. Master tables and curves for Vertical Electrical Sounding (VES) over layered structures, Madrid Interciecia.

10. Gonos, I.F. and I.A. Stathopulos, 2005. Estimation of multilayer soil parameters using genetic algorithms. IEEE Trans. Power Delivery, 20: 100-106.

11. Chow, Y.L., M.M. Elsherbiny and M.M.A. Salama, 1996. Resistance formulas of grounding systems in two-layer earth. IEEE Trans. Power Delivery, 11: 1330-1336. 